\title{
Increased risk of gastric adenocarcinoma after treatment of primary gastric diffuse large B-cell lymphoma
}

Koji Inaba ${ }^{1 *}$, Ryoji Kushima ${ }^{2}$, Naoya Murakami ${ }^{1}$, Yuuki Kuroda ${ }^{1}$, Ken Harada ${ }^{1}$, Mayuka Kitaguchi $^{1}$, Kotaro Yoshio $^{1}$, Shuhei Sekii ${ }^{1}$, Kana Takahashi ${ }^{1}$, Madoka Morota ${ }^{1}$, Hiroshi Mayahara ${ }^{1}$, Yoshinori Ito ${ }^{1}$, Minako Sumi ${ }^{1}$, Takashi Uno ${ }^{3}$ and Jun Itami ${ }^{1}$

\begin{abstract}
Background: There have been sporadic reports about synchronous as well as metachronous gastric adenocarcinoma and primary gastric lymphoma. Many reports have dealt with metachronous gastric adenocarcinoma in mucosa-associated lymphoid tissue lymphoma of stomach. But to our knowledge, there have been no reports that document the increased incidence of metachronous gastric adenocarcinoma in patients with gastric diffuse large B-cell lymphoma. This retrospective study was conducted to estimate the incidence of metachronous gastric adenocarcinoma after primary gastric lymphoma treatment, especially in diffuse large B-cell lymphoma.
\end{abstract}

Methods: The retrospective cohort study of 139 primary gastric lymphoma patients treated with radiotherapy at our hospital. Mean observation period was 61.5 months (range: 3.7-124.6 months). Patients profile, characteristics of primary gastric lymphoma and metachronous gastric adenocarcinoma were retrieved from medical records. The risk of metachronous gastric adenocarcinoma was compared with the risk of gastric adenocarcinoma in Japanese population.

Results: There were 10 (7.2\%) metachronous gastric adenocarcinoma patients after treatment of primary gastric lymphomas. It was quite high risk compared with the risk of gastric carcinoma in Japanese population of $54.7 / 100,000$. Seven patients of 10 were diffuse large B-cell lymphoma and other 3 patients were mixed type of diffuse large B-cell lymphoma and mucosa associated lymphoid tissue lymphoma. Four patients of 10 metachronous gastric adenocarcinomas were signet-ring cell carcinoma and two patients died of gastric adenocarcinoma. Metachronous gastric adenocarcinoma may have a more malignant potential than sporadic gastric adenocarcinoma. Old age, Helicobacter pylori infection and gastric mucosal change of chronic gastritis and intestinal metaplasia were possible risk factors for metachronous gastric adenocarcinoma.

Conclusion: There was an increased risk of gastric adenocarcinoma after treatment of primary gastric lymphoma, especially of diffuse large B-cell lymphoma.

Keywords: Gastric lymphoma, Metachronous gastric adenocarcinoma, Diffuse large B-cell lymphoma, Radiotherapy

\footnotetext{
* Correspondence: koinaba@ncc.go.jp

'Department of Radiation Oncology, National Cancer Center Hospital, 5-1-1

Tsukiji, Chuo-ku, Tokyo 104-0045, Japan

Full list of author information is available at the end of the article
} 


\section{Background}

There have been sporadic reports about synchronous as well as metachronous gastric adenocarcinoma (GA) and primary gastric lymphoma (PGL) [1-16]. Regarding synchronous GA and PGL, Ishihama et al. reported that GA was seen synchronously in $3.3 \%$ of PGL patients (4/121 patients) [8]. Concerning the metachronous GA and PGL, the largest study is that of Capelle LG et al. which reported that metachronous GA risk was six times higher in the patients with gastric mucosa associated lymphoid tissue (MALT) lymphoma than in the Dutch general population [16]. Many reports have dealt with metachronous GA in MALT lymphoma of stomach. But to our knowledge, there have been no reports that document the increased incidence of metachronous GA in patients with gastric diffuse large B-cell lymphoma (DLBCL). This retrospective study was conducted to estimate the incidence of metachronous GA after PGL treatment, especially in DLBCL.

\section{Methods}

The radiation oncology department database from 2000 to 2010 was searched for PGL patients who underwent radiotherapy. Patient's profiles at the time of PGL diagnosis (age, sex, lymphoma histology, stage, treatment and outcome) were retrieved retrospectively. After treatment of PGL, patients underwent regular follow-ups including endoscopic examinations and CT scannings. The date of GA diagnosis, interval between PGL and GA, stage of GA, treatment of GA and outcome were also investigated. One of the authors, an experienced gastrointestinal pathologist, reviewed the biopsy slides at the time of PGL and GA diagnosis and the presence of atrophic gastritis and intestinal metaplasia was diagnosed. In the 10 patients with metachronous GA after PGL, the presence of Helicobacter pylori (HP) infection was diagnosed retrospectively by pathology findings of the biopsy specimens or by results of the various laboratory tests.

Estimated risk of GA after PGL was calculated in comparison to the incidence of GA in Japanese population. Our institutional review board (National Cancer Center Institutional Review Board) approved this study.

\section{Results}

There were 139 patients with PGL (MALT lymphoma in 51 patients, DLBCL in 83, peripheral T-cell lymphoma

Table 1 Patient's characteristic and PGL treatment

\begin{tabular}{|c|c|c|c|c|c|c|c|c|}
\hline \multirow{3}{*}{$\begin{array}{c}\mathrm{N} \\
\text { Age }\end{array}$} & & & \multicolumn{2}{|c|}{ DLBCL } & \multicolumn{2}{|c|}{ MALT lymphoma } & \multicolumn{2}{|c|}{ Others } \\
\hline & \multicolumn{2}{|c|}{139} & \multicolumn{2}{|c|}{83} & \multicolumn{2}{|c|}{51} & \multicolumn{2}{|c|}{5 (ATL 2, FL 2, PTCL 1) } \\
\hline & \multicolumn{2}{|c|}{ Median 62 ( range: $19-85$ ) } & \multicolumn{2}{|c|}{ Median 63 ( range: $20-85$ ) } & \multicolumn{2}{|c|}{ Median 56 ( range: 19-76) } & \multicolumn{2}{|c|}{ Median 64 ( range: $53-72$} \\
\hline $\operatorname{Sex}(M: F)$ & \multicolumn{2}{|c|}{$71: 68$} & \multicolumn{2}{|c|}{$44: 39$} & \multicolumn{2}{|c|}{$25: 26$} & \multicolumn{2}{|c|}{$2: 3$} \\
\hline Stage & I & 94 & । & 42 & I & 48 & । & 4 \\
\hline \multirow[t]{2}{*}{ (Lugano) } & $\|$ & 40 & $\|$ & 37 & $\|$ & 2 & $\|$ & 1 \\
\hline & IV & 5 & IV & 4 & IV & 1 & & \\
\hline \multirow[t]{2}{*}{ Treatment } & RT & 50 & RT & 0 & RT & 49 & RT & 1 \\
\hline & $\mathrm{CT}+\mathrm{RT}$ & 89 & $C T+R T$ & 83 & $C T+R T$ & 2 & $C T+R T$ & 4 \\
\hline \multirow[t]{2}{*}{ Rituximab } & $\mathrm{R}+$ & 40 & $\mathrm{R}+$ & 38 & $\mathrm{R}+$ & 1 & $\mathrm{R}+$ & 1 \\
\hline & $\mathrm{R}^{-}$ & 99 & $\mathrm{R}^{-}$ & 45 & R- & 50 & R- & 4 \\
\hline \multirow[t]{5}{*}{ RT dose } & & & $40 \mathrm{~Gy} / 20 \mathrm{fr}$ & 35 & $30 \mathrm{~Gy} / 15 \mathrm{fr}$ & 23 & $40 \mathrm{~Gy} / 20 \mathrm{fr}$ & 2 \\
\hline & $40 \mathrm{~Gy} \geqq$ & 89 & $40.5 \mathrm{~Gy} / 27 f$ & 45 & $30 \mathrm{~Gy} / 20 \mathrm{fr}$ & 24 & $40.5 \mathrm{~Gy} / 27 \mathrm{fr}$ & 2 \\
\hline & $40 \mathrm{~Gy}<$ & 50 & $44 \mathrm{~Gy} / 22 \mathrm{fr}$ & 2 & $36 \mathrm{~Gy} / 18 \mathrm{fr}$ & 1 & $36 \mathrm{~Gy} / 18 \mathrm{fr}$ & 1 \\
\hline & & & $30 \mathrm{~Gy} / 15 \mathrm{fr}$ & 1 & $40 \mathrm{~Gy} / 20 \mathrm{fr}$ & 1 & & \\
\hline & & & & & $46 \mathrm{~Gy} / 23 \mathrm{fr}$ & 2 & & \\
\hline Observation length & \multicolumn{2}{|c|}{ mean 61.5 months } & \multicolumn{2}{|c|}{ mean 62.7 months } & \multicolumn{2}{|c|}{ mean 61.0 months } & \multicolumn{2}{|c|}{ mean 46.9 months } \\
\hline (range) & \multicolumn{2}{|c|}{$(3.7-124.6)$} & \multicolumn{2}{|c|}{$(7.1-124.6)$} & \multicolumn{2}{|c|}{$(3.7-120.4)$} & \multicolumn{2}{|c|}{$(11.5-82.4)$} \\
\hline 5 year OS & \multicolumn{2}{|c|}{$92.0 \%$} & \multicolumn{2}{|c|}{$89.6 \%$} & \multicolumn{2}{|c|}{$97.7 \%$} & \multicolumn{2}{|c|}{$75.0 \%$} \\
\hline
\end{tabular}

PGL: primary gastric lymphoma.

DLBCL: diffuse large B-cell lymphoma.

MALT: mucosa-associated lymphoid tissue.

ATL: adult T-cell lymphoma.

FL: follicular lymphoma.

PTCL: peripheral T-cell lymphoma.

$\mathrm{RT}$ : radiotherapy.

$\mathrm{CT}$ : chemotherapy.

OS: overall survival.

R: rituximab. 
(PTCL) in one, adult T-cell lymphoma (ATL) in 2 and follicular lymphoma (FL) in 2). Eighteen patients with MALT lymphoma were treated by radiation therapy because of the residual tumors after HP eradication, and the remaining 33 patients underwent radiation therapy because they were HP negative. Patient characteristics are shown in Table 1. Mean observation length was 61.5 months (range: 3.7-124.6 months). All PGLs in the current study were treated by radiotherapy and almost all patients except MALT were treated with chemoradiotherapy. There were seen 10 patients with GA developed after treatment of PGL. No synchronous GA was found in this study. Tables 2 and 3 show the details of metachronous GA. The mean latent period between PGL and GA was 43.1 months (range: 7.9-90.8 months) (Figure 1). The histological types of GA were well

Table 2 Metachronous GA and details

\begin{tabular}{|c|c|c|c|c|c|c|c|c|c|c|}
\hline No & Age & Sex & $\begin{array}{c}\text { PGL } \\
\text { pathology }\end{array}$ & $\begin{array}{l}\text { Lugano } \\
\text { stage }\end{array}$ & Tx for PGL & $\begin{array}{l}\text { Interval (months) } \\
\text { from PGL to GA }\end{array}$ & $\begin{array}{c}\text { GA } \\
\text { pathology }\end{array}$ & $\begin{array}{l}\text { Stage } \\
\text { for GA }\end{array}$ & Tx for GA & Outcome \\
\hline \multirow[t]{3}{*}{1} & 72 & $\mathrm{~F}$ & DLBCL & 111 & $\mathrm{CHOP} \times 3$ & 42.6 & sig & $m$ & distal gastrectomy & Alive for $3.7 \mathrm{~m}$ after $\mathrm{GA}$ \\
\hline & & & & & + & & & & & \\
\hline & & & & & $40 \mathrm{~Gy} / 20 \mathrm{fr}$ & & & & & \\
\hline \multirow[t]{3}{*}{2} & 62 & M & DLBCL & I & $\mathrm{CHOP} \times 3$ & 64.3 & W/D AC & $\mathrm{m}$ & ESD & Alive for $47.7 \mathrm{~m}$ after $\mathrm{GA}$ \\
\hline & & & & & + & & & & & \\
\hline & & & & & $40.5 \mathrm{~Gy} / 27 \mathrm{fr}$ & & & & & \\
\hline \multirow[t]{3}{*}{3} & 70 & M & DLBCL & $\| 1$ & $\mathrm{CHOP} \times 3$ & 45.9 & W to M/D AC & $\mathrm{m}$ & ESD & Alive for $71.6 \mathrm{~m}$ after $\mathrm{GA}$ \\
\hline & & & & & + & & & & & \\
\hline & & & & & $40.5 \mathrm{~Gy} / 27 \mathrm{fr}$ & & & & & \\
\hline \multirow[t]{3}{*}{4} & 68 & $\mathrm{~F}$ & DLBCL & 1 & $\mathrm{CHOP} \times 3$ & 90.8 & W/D AC & $\mathrm{m}$ & ESD & Alive for $31.8 \mathrm{~m}$ after $\mathrm{GA}$ \\
\hline & & & & & + & & & & & \\
\hline & & & & & $40.5 \mathrm{~Gy} / 27 \mathrm{fr}$ & & & & & \\
\hline \multirow[t]{3}{*}{5} & 70 & M & DLBCL & 111 & $\mathrm{CHOP} \times 3$ & 16.0 & W/D AC & $\mathrm{sm}$ & EMR $\rightarrow$ partial & Dead for 36.9 m after GA \\
\hline & & & & & + & & & & gastrectomy & \\
\hline & & & & & $40.5 \mathrm{~Gy} / 27 \mathrm{fr}$ & & & & & \\
\hline \multirow[t]{3}{*}{6} & 63 & M & DLBCL & IV & $\mathrm{R} \times 8-\mathrm{CHOP} \times 8$ & 30.2 & W to P/D AC & se & total gastrectomy & Dead for $12.0 \mathrm{~m}$ after GA \\
\hline & & & & & + & & & & & \\
\hline & & & & & $40.5 \mathrm{~Gy} / 27 \mathrm{fr}$ & & & & & \\
\hline \multirow[t]{3}{*}{7} & 36 & M & MALT & $\| 1$ & $\mathrm{R} \times 8-\mathrm{CHOP} \times 3$ & 42.1 & sig & m & partial gastrectomy & Alive for $20.6 \mathrm{~m}$ after GA \\
\hline & & & + & & + & & & & & \\
\hline & & & DLBCL & & $40 \mathrm{G} \mathrm{y} / 20 \mathrm{fr}$ & & & & & \\
\hline \multirow[t]{3}{*}{8} & 63 & M & DLBCL & $\| 1$ & $\mathrm{R} \times 8-\mathrm{CHOP} \times 6$ & 73.7 & sig & $\mathrm{m}$ & EMR & Alive for $16.6 \mathrm{~m}$ after $\mathrm{GA}$ \\
\hline & & & & & + & & & & & \\
\hline & & & & & $40.5 \mathrm{~Gy} / 27 \mathrm{fr}$ & & & & & \\
\hline \multirow[t]{3}{*}{9} & 66 & $\mathrm{~F}$ & MALT & $\| 1$ & $\mathrm{CHOP} \times 3$ & 17.5 & sig & $\mathrm{m}$ & EMR & Alive for $69.3 \mathrm{~m}$ after $\mathrm{GA}$ \\
\hline & & & + & & + & & & & & \\
\hline & & & DLBCL & & $40.5 \mathrm{~Gy} / 27 \mathrm{fr}$ & & & & & \\
\hline \multirow[t]{3}{*}{10} & 73 & $\mathrm{~F}$ & MALT & I & $\mathrm{CHOP} \times 4$ & 7.9 & W/D AC & $\mathrm{m}$ & EMR & Alive for $70.2 \mathrm{~m}$ after $\mathrm{GA}$ \\
\hline & & & + & & + & & & & & \\
\hline & & & DLBCL & & $40.5 \mathrm{~Gy} / 27 \mathrm{fr}$ & & & & & \\
\hline
\end{tabular}

sig: signet-ring cell carcinoma.

W/D: well differentiated.

M/D: moderately differentiated.

P/D: poorly differentiated.

AC: adenocarcinoma.

PGL: primary gastric lymphoma.

R: rituximab.

Tx: treatment.

GA: gastric adenocarcinoma.

CHOP: cyclophosphamide, hydroxydaunorubicin, vincristine and prednisolone. 
Table 3 Metachronous GA and pathologic change

\begin{tabular}{cccccc}
\hline No & $\begin{array}{c}\text { Gastric } \\
\text { mucosa } \\
\text { at PGL }\end{array}$ & $\begin{array}{c}\text { Intestinal } \\
\text { metaplasia } \\
\text { at PGL }\end{array}$ & $\begin{array}{c}\text { Gastric } \\
\text { mucosa } \\
\text { at GA }\end{array}$ & $\begin{array}{c}\text { Intestinal } \\
\text { metaplasia } \\
\text { at GA }\end{array}$ & HP infection \\
\hline 1 & atorophic & + & atorophic & + & possible \\
2 & atorophic & + & atorophic & + & + \\
3 & atorophic & + & atorophic & + & possible \\
4 & atorophic & + & atorophic & + & + \\
5 & atorophic & - & atorophic & + & + \\
6 & atorophic & - & atorophic & + & possible \\
7 & normal & - & atorophic & + & + \\
8 & atorophic & - & atorophic & + & + \\
9 & atorophic & + & atorophic & + & possible \\
10 & atorophic & + & atorophic & + & possible \\
\hline
\end{tabular}

HP infection possible means background gastric mucosal changes suggesting HP infection.

differentiated adenocarcinoma in 4 patients, well to moderate differentiated adenocarcinoma in one, well to poorly differentiated adenocarcinoma in one, and signetring cell carcinoma in 4. In 9 patients, GA was classified as stage I and the remaining one was diagnosed as stage II. About the lymphoma histology, seven patients were classified as DLBCL and the remaining 3 showed a mixture of DLBCL and MALT lymphoma. For the GA, endoscopic resection was performed in 6 patients with no relapses. Four patients underwent surgery with relapses seen in 2 patients. Both of them succumbed to distant metastasis 9 and 37 months after surgery despite chemotherapy. Two- and 5-year overall survivals of GA were $90.0 \%$ and $75.0 \%$. The 5 -year overall survivals of DLBCL and MALT lymphoma were $89.6 \%$ and $97.7 \%$ respectively. Eight of the 83 DLBCL patients died, of which 5 were from non-lymphoma causes. Two of the 5 died from metachronous GA.

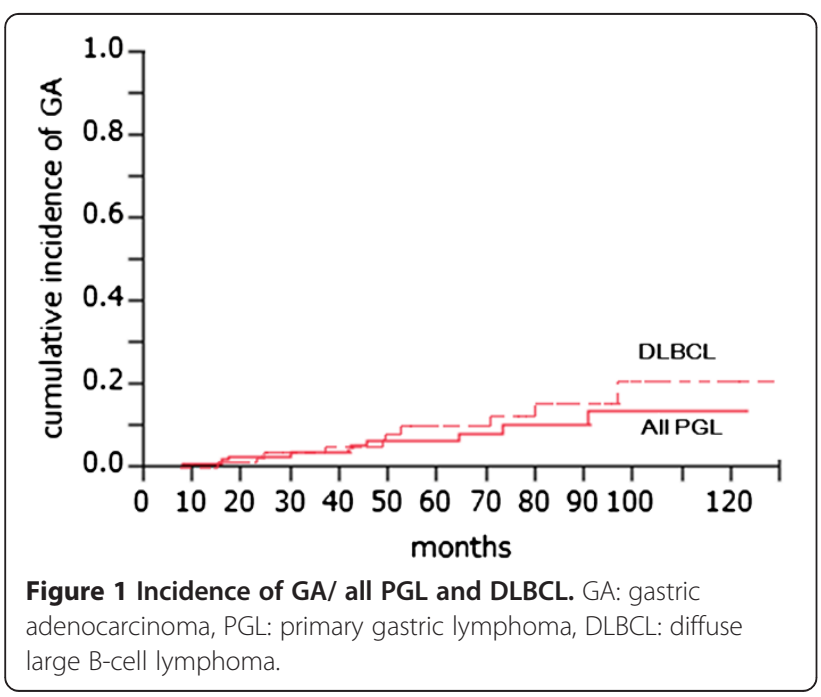

In the 10 patients with metachronous GA after PGL, mucosal findings at the time of PGL showed atrophic gastritis in 9 patients and intestinal metaplasia in 6. In contrast, the mucosa at the time of GA diagnosis showed atrophic gastritis and intestinal metaplasia in all 10 patients. Of 10 patients who developed GA after PGL, 5 had HP infection, and the remaining 5 patients had no information of HP infection but the background gastric mucosal changes of atrophic gastritis and intestinal metaplasia suggested possible presence of HP infection (Table 3).

Table 4 compared factors between the whole patients and the patients with metachronous GA. The incidence of metachronous GA was higher in the patients with age

Table 4 The comparison with metachronous GA and without metachronous GA

\begin{tabular}{|c|c|c|c|c|c|}
\hline & $\mathrm{n}$ & $\begin{array}{c}\text { Metachronous } \\
\text { GA+ }\end{array}$ & $\begin{array}{c}p \\
\text { value }\end{array}$ & $\begin{array}{l}\text { Odds } \\
\text { ratio }\end{array}$ & $95 \% \mathrm{Cl}$ \\
\hline \multicolumn{6}{|l|}{ Sex } \\
\hline M & 71 & $6(8 \%)$ & \multirow{2}{*}{0.4} & \multirow{2}{*}{1.47} & \multirow{2}{*}{$0.40-5.48$} \\
\hline $\mathrm{F}$ & 68 & $4(6 \%)$ & & & \\
\hline \multicolumn{6}{|l|}{ Age } \\
\hline $60 \leqq$ & 64 & $1(2 \%)$ & \multirow{2}{*}{$0.02 \%$} & \multirow{2}{*}{8.59} & \multirow{2}{*}{$1.06-69.78$} \\
\hline $60>$ & 75 & $9(12 \%)$ & & & \\
\hline \multicolumn{6}{|l|}{$\begin{array}{l}\text { Histology of } \\
\text { Lymphoma }\end{array}$} \\
\hline $\mathrm{DLBCL}$ & 83 & $10(12 \%)$ & \multirow{2}{*}{$0.007^{※}$} & \multirow{2}{*}{-} & \multirow{2}{*}{-} \\
\hline MALT & 51 & 0 & & & \\
\hline \multicolumn{6}{|l|}{ HP Infection } \\
\hline HP positive & 22 & $5(23 \%)$ & \multirow{2}{*}{$0.007 *$} & \multirow{2}{*}{-} & \multirow{2}{*}{ - } \\
\hline HP negative & 34 & 0 & & & \\
\hline \multicolumn{6}{|l|}{ Chemotherapy } \\
\hline Yes & 88 & $10(11 \%)$ & \multirow{2}{*}{$0.009 *$} & \multirow{2}{*}{-} & \multirow{2}{*}{-} \\
\hline No & 51 & 0 & & & \\
\hline \multicolumn{6}{|l|}{ Rituximab } \\
\hline Yes & 40 & $3(8 \%)$ & \multirow{2}{*}{0.59} & \multirow{2}{*}{1.07} & \multirow{2}{*}{$0.26-4.34$} \\
\hline No & 99 & $7(7 \%)$ & & & \\
\hline \multicolumn{6}{|l|}{ Stage } \\
\hline Stage I & 93 & $3(3 \%)$ & \multirow{2}{*}{$0.02 \%$} & \multirow{2}{*}{5.38} & \multirow{2}{*}{$1.32-21.92$} \\
\hline Stage II-IV & 46 & 7 (15\%) & & & \\
\hline \multicolumn{6}{|l|}{ Chronic Gastritis } \\
\hline Yes & 65 & $9(14 \%)$ & \multirow{2}{*}{0.26} & \multirow{2}{*}{3.05} & \multirow{2}{*}{$0.36-25.71$} \\
\hline No & 20 & $1(5 \%)$ & & & \\
\hline $\begin{array}{l}\text { Intestinal } \\
\text { Metaplasia }\end{array}$ & & & & & \\
\hline Yes & 29 & $6(21 \%)$ & 007 & 330 & 0871217 \\
\hline No & 56 & $4(7 \%)$ & 0.07 & 3.39 & $0.8 /-13.11$ \\
\hline
\end{tabular}

GA: gastric adenocarcinoma.

$\mathrm{Cl}$ : confidence interval.

※ $p<0.05$. 
over 60 years, DLBCL, presence of HP infection, chemotherapy and stage II-IV with a statistical significance and the presence of intestinal metaplasia of gastric mucosa with a marginal significance $(\mathrm{p}=0.07)$.

The risk of metachronous GA after PGL was 10/139 $(=7.2 \%)$. If confined to DLBCL, the risk was $10 / 83$ $(=12.0 \%)$ (Figure 1). The risk of GA in Japanese population is about 54.7/100,000 [17]. The relative risk was 131 (95\% confidence interval: 68-251). If confined to DLBCL, the relative risk was 219 (95\% confidence interval: 116-415).

\section{Discussion}

There were 10 patients developing metachronous GA after treatment of PGL. The risk of metachronous GA was higher in the patients with age over 60 years, DLBCL, HP infection, use of chemotherapy, Stage II-IV of PGL. In this study, MALT lymphomas were treated by radiation therapy after HP eradication as described in European Gastro-Intestinal Lymphoma Study (EGILS) group consensus report [18]. HP eradication and HP negative may explain that MALT lymphomas in this study showed no increased risk of metachronous GA. Increased risk of GA in Stage II-IV and patients treated with chemotherapy can be explained by the fact that only the patients with DLBCL showed advanced stages and treated by chemotherapy. Multivariate analysis to estimate factors for metachronous GA showed no statistical significance due to small number.

HP infection is well known in causing atrophic gastritis and intestinal metaplasia which might lead to GA. Not only the ongoing HP infection, but also radiation and chemotherapy could have contributed the mucosal change.

Old patients with primary gastric diffuse large B-cell lymphoma (PGDLBCL) who remains HP-infection positive and have mucosal change of atrophic gastritis and intestinal metaplasia should be followed up cautiously early to find metachronous GA and eradication of HP infection should be considered.

The increased risk of GA after PGL might be possibly explained by 2 theories. One is that damages to gastric mucosa by HP infection, chemotherapy, or radiotherapy increase GA risk [19-21], and the other is that GA remained undetected at the time of PGL because GA was so small [22-24]. Risk of treatment-related solid cancer increases more than 5 years after the primary treatment. The interval of GA and PGL was within 5 years in 7 patients. These patients with short interval may have undetected small GA at the time of PGL and the patients with longer interval could be caused by continuing HP infection and/or treatment.

To our knowledge, this is the first report which has large number of PGL and longtime follow-up and shows the high risk of GA after treatment of PGL, especially in DLBCL.

Regarding the nature of GA after PGL, cancerous infiltration was only up to mucosal layer in 8 patients. This early detection was due to the short intervals between endoscopic examinations for PGL follow-ups. However, 4 of 10 patients had signet-ring cell carcinomas that had a more aggressive behavior than differentiated adenocarcinoma. Additionally, 2 patients with submucal and serosal infiltrations succumbed to distant metastasis after gastrectomy with 2 year and 5 year overall survival of 90.0\% and $75.0 \%$, respectively. GA after PGL may have more malignant potential than sporadic GA.

\section{Conclusion}

There were 10 patients of metachronous GA after PGL and the risk of metachronous GA after PGDLBCL was 10/83(=12.0\%). GA after PGL may have more malignant potential than sporadic GA. Eradication of HP infection should be considered in PGL to reduce the risk of GA.

\section{Competing interests}

The authors declare that they have no competing interests.

\section{Authors' contributions}

$\mathrm{KI}, \mathrm{YK}, \mathrm{MM}, \mathrm{HM}, \mathrm{YI}, \mathrm{MS}$, TU and JI have made substantial contributions to conception and design. Kl, TU and Jl have been involved in drafting the manuscript or revising it critically for important intellectual content. RK carried out the pathologic examination. $\mathrm{Kl}, \mathrm{NM}, \mathrm{KH}, \mathrm{MK}, \mathrm{KY}, \mathrm{SS}$ and $\mathrm{KT}$ participated in acquisition of data and interpretation of data. All authors read and approved the final manuscript.

\section{Author details}

'Department of Radiation Oncology, National Cancer Center Hospital, 5-1-1 Tsukiji, Chuo-ku, Tokyo 104-0045, Japan. ${ }^{2}$ Department of Pathology and Clinical Laboratories, Pathology Division, National Cancer Center Hospital, 5-1-1 Tsukiji Chuo-ku, Tokyo 104-0045, Japan. ${ }^{3}$ Diagnostic Radiology and Radiation Oncology, Graduate School of Medicine, Chiba University, 1-8-1, Inohana, Chuo-ku, Chiba City, Chiba 260-8670, Japan.

Received: 18 February 2013 Accepted: 12 September 2013 Published: 26 October 2013

\section{References}

1. Kasahara Y, Takemoto M, Morishita A, Kuyama T, Takahashi M, Tanji K: Coexisting adenocarcinoma and malignant lymphoma of the stomach: case report and review of the Japanese literature. Am J Gastroenterol 1988, 83:190-193.

2. Noda T, Akashi H, Matsueda S, Katsuki N, Shirahashi K, Kojiro M: Collision of malignant lymphoma and multiple early adenocarcinomas of the stomach. Arch Pathol Lab Med 1989, 113:419-422.

3. Nakamura S, Aoyagi K, Iwanaga S, Yao T, Tsuneyoshi M, Fujishima M: Synchronous and metachronous primary gastric lymphoma and adenocarcinoma: a clinicopathological study of 12 patients. Cancer 1997, 79:1077-1085.

4. Akosa AB, Clark DM, Desa L: Synchronous adenocarcinoma and primary malignant lymphoma of the stomach. Postgrad Med J 1990, 66:778-780.

5. Wotherspoon AC, Isaacson PG: Synchronous adenocarcinoma and low grade B-cell lymphoma of mucosa associated lymphoid tissue (MALT) of the stomach. Histopathology 1995, 27:325-331.

6. Nishino N, Konno H, Baba S, Aoki K, Nishimura T, Arai T, Kino I: Synchronous lymphoma and adenocarcinoma occurring as a collision tumor in the stomach: report of a case. Surg Today 1996, 26:508-512. 
7. Hardman WJ 3rd, Gal AA, Pascal RR: Gastric adenocarcinoma and low-grade B-cell lymphoma of mucosa-associated lymphoid tissue. South Med J 1997, 90:426-430.

8. Ishihama T, Kondo H, Saito D, Yamaguchi H, Shirao K, Yokota T, Hosokawa K, Ono H, Iwabuchi M, Gotoda T, Matsuno Y, Boku N, Ohtsu A, Yoshida S: Clinicopathological studies on coexisting gastric malignant lymphoma and gastric adenocarcinoma: report of four cases and review of the Japanese literature. Jpn J Clin Oncol 1997, 27:101-106.

9. Kaffes A, Hughes L, Hollinshead J, Katelaris P: Synchronous primary adenocarcinoma, mucosa-associated lymphoid tissue lymphoma and a stromal tumor in a Helicobacter pylori-infected stomach. J Gastroenterol Hepatol 2002, 17:1033-1036.

10. Sakai T, Ogura Y, Narita J, Suto T, Kimura D, Ainai S, Fujita H, Kamada M: Simultaneous early adenocarcinoma and mucosa-associated lymphoid tissue (MALT) lymphoma of the stomach associated with Helicobacter pylori infection. Gastric Cancer 2003, 6:191-196.

11. Suenaga M, Ohta K, Toguchi M, Sato T, Ohyama S, Yamaguchi T, Muto T, Yanagisawa A, Kato Y: Colliding gastric and intestinal phenotype welldifferentiated adenocarcinoma of the stomach developing in an area of MALT-type lymphoma. Gastric Cancer 2003, 6:270-276.

12. Sellin J, Levin B, Reckard C, Riddell R: Gastric adenocarcinoma following gastric lymphoma. Role of partial gastrectomy. Cancer 1980, 45:996-1000.

13. Brumback RA, Gerber JE, Hicks DG, Strauchen JA: Adenocarcinoma of the stomach following irradiation and chemotherapy for lymphoma in young patients. Cancer 1984, 54:994-998.

14. Zorlu AF, Atahan IL, Gedikoglu G, Ruacan S, Sayek I, Tekuzman G: Does gastric adenocarcinoma develop after the treatment of gastric lymphoma? J Surg Oncol 1993, 54:126-131.

15. Zauber NP, Berman EL: Synchronous and metachronous primary gastric lymphoma and adenocarcinoma: a clinicopathologic study of 12 patients. Cancer 1998, 82:226-227.

16. Capelle LG, de Vries AC, Looman CWN, Casparie MK, Boot H, Meijer GA, Kuipers EJ: Gastric MALT lymphoma: epidemiology and high adenocarcinoma risk in a nation-wide study. Eur J Cancer 2008, 44:2470-2476

17. Cancer incidence and incidence rates in Japan. Center for Cancer Control and Information Services, National Cancer Center, Japan [http://ganjoho.jp/pro/ statistics/en/table_download.html]

18. Ruskone-Fourmestraux A, Fischbach W, Aleman BM, Boot H, Du MQ, Megraud F, Montalban C, Raderer M, Savio A, Wotherspoon A: EGILS consensus report. Gastric extranodal marginal zone B-cell lymphoma of MALT. Gut 2011, 60:747-758.

19. Hamaloglu E, Topaloglu S, Ozdemir A, Ozenc A: Synchronous and metachronous occurrence of gastric adenocarcinoma and gastric lymphoma: a review of the literature. World I Gastroenterol 2006, 12:3564-3574

20. Kellum JM Jr, Jaffe BM, Calhoun TR, Ballinger WF 2nd: Gastric complications after radiotherapy for Hodgkin's disease and other lymphomas. Am J Surg 1977, 134:314-317.

21. Brown WM, Doll R: Mortality from cancer and other causes after radiotherapy for ankylosing spondylitis. Br Med J 1965, 2:1327-1332.

22. Abe S, Oda I, Kinjyou Y, Suzuki H, Nonaka S, Yoshinaga S, Makazu M, Sou E, Yachida T, Yamada M, Nakamura Y, Taniguchi H, Sekine S, Kushima R: Case report of early gastric cancer which can be diagnosed easily after Helicobacter Pylori eradication (written in Japanese). Stomach and intestine 2012, 47:1695-1699.

23. Kato M, Ono S, Takahashi M, Shinada K, Haneda M, Yamamoto K, Yoshida T, Mabe K, Shimizu Y, Asaka M, Mori Y, Nakagawa M, Nakagawa S: Multiple gastric carcinoma after Helicobacter pylori eradication (written in Japanese). Stomach and intestine 2011, 46:75-82.

24. Haruma K, Suzuki T, Tsuda T, Yoshihara M, Sumii K, Kajiyama G: Evaluation of tumor growth rate in patients with early gastric carcinoma of the elevated type. Gastrointest Radiol 1991, 16:289-292.

\section{doi:10.1186/1471-2407-13-499}

Cite this article as: Inaba et al:: Increased risk of gastric adenocarcinoma after treatment of primary gastric diffuse large B-cell lymphoma. BMC Cancer 2013 13:499. 